\title{
Chapter 4 \\ Business Models with Additive \\ Manufacturing-Opportunities and Challenges from the Perspective of Economics and Management
}

\section{Frank T. Piller, Christian Weller and Robin Kleer}

\begin{abstract}
Technological innovation has frequently been shown to systematically change market structure and value creation. Additive manufacturing (AM), or, colloquially 3D printing, is such a disruptive technology (Berman 2012; Vance 2012). Economic analysis of AM still is scarce and has predominantly focused on production cost or other firm level aspects (e.g., Mellor et al. 2014; Petrovic et al. 2011; Ruffo and Hague 2007), but has neglected the study of AM on value creation and market structure. In this paper, we want to discuss the economic effects of AM on the locus of innovation and production. This is why we first review some current business models that successfully use AM as a source of value creation. Being a potential disruptive influence on market structures, we then discuss how AM may enable a more local production by users, supplementing the recent development of an upcoming infrastructure for innovating users and "Makers".
\end{abstract}

\subsection{Introduction}

Recently, it has been highlighted that additive manufacturing (AM) technology has the potential to spark a new industrial revolution by extending the features of conventional production systems (Atzeni and Salmi 2012; Berman 2012; Mellor et al. 2014; The Economist 2011). But AM technology affects market structure beyond direct effects on a single firm's production processes. There is a growing community of "Makers" who develop and share 3D models, sell 3D printed products on marketplaces, and even develop and provide their own 3D printers for home usage (De Jong and de Bruijn 2013; Gershenfeld 2005; Lipson and Kurman 2013). Furthermore, a steadily growing number of $3 \mathrm{D}$ printers for home and industrial use extends the scale and scope of manufacturing options. Only two years ago, industry

F.T. Piller $(\bowtie) \cdot$ C. Weller $\cdot$ R. Kleer

TIME Research Area, TIM Group, RWTH Aachen University,

Kackertstraße 7, 52072 Aachen, Germany

e-mail: piller@time.rwth-aachen.de

(C) The Author(s) 2015

C. Brecher (ed.), Advances in Production Technology,

Lecture Notes in Production Engineering, DOI 10.1007/978-3-319-12304-2_4 
analyst Gartner (2012) argued that AM is at its "peak of inflated expectations," noting that the technology is still too immature to satisfy such high expectations. More recently, however, Gartner (2014) predicted that industrial use of AM is likely to reach a level of mainstream adaptation between 2016 and 2020.

AM technology has been in use since the 1980s. In the early phase, the application of AM technology was basically limited to the production of prototypes. The technology's primary goal was to offer an affordable and fast way to receive tangible feedback during the product development process; prototypes were usually not functional (Gibson et al. 2010). Today, prototyping via AM has become a common practice in many firms. The far greater opportunity of AM, however, and the reason behind its current hype, is its promise to replace conventional production technologies for serial manufacturing of components or products ("rapid manufacturing", Gibson et al. 2010). The latter application also bears numerous opportunities for business model innovation.

\subsection{Technological Characteristics Driving AM's Economic Impact}

Ongoing standardization efforts aim to find a coherent terminology for the various AM technologies in use today. Generally, AM refers to "the process of joining materials to make objects from 3D model data, usually layer upon layer" (ASTM International 2012). There is a variety of different manufacturing processes behind the general term AM. These processes can largely differ in the available choice of materials, build rates, the mechanical properties of the produced parts and other technological constraints. Thus, certain application fields are usually associated with either of these processes. As a result, one cannot refer to the AM technology. This is why further economic analysis in this paper aims to generalise some basic principles that characterise AM as a new production technology available for industrial and personal uses.

The main benefit of AM technology is that it enables the flexible production of customized products without cost penalties in manufacturing. It does so by using direct digital manufacturing processes that directly transform 3D data into physical parts, without any need for tools or moulds. Additionally, the layer manufacturing principle can also produce functionally integrated parts in a single production step, hence reducing the need for assembly activities. Thus, AM technology significantly affects the costs of flexibility, individualisation, capital costs, and marginal production costs (Berman 2012; Dolgui and Proth 2010; Koren 2006).

Nonetheless, the opportunities of AM come with a number of limitations: available materials do not always match the characteristics of conventional manufacturing processes, the production throughput speed is rather low, most manufactures still demand an additional surface finish, and common standards for quality control are not established yet (Berman 2012; Gibson et al. 2010). While the former limitations may be of temporary nature, diminishing with technological development, 
there is a larger inherent threat of AM: In combination with improved 3D-scanning and reverse-engineering capabilities, AM also poses severe risks to the intellectual property rights of product designs (Kurfess and Cass 2014). In the end, AM means digital production, starting with full digital representations of the output. Copying a physical product and converting it into shareable 3D design data might become as easy as copying a printed document or sharing ordinary computer files - similar developments led to disruptive change in the music industry (Wilbanks 2013). The issue of property rights in an age of digital product designs is one of the most severe economic consequences of AM. In the end, we believe it will be the clever design of ecosystems and business models, turning this threat into an opportunity, which will determine the economic potential of AM.

\subsection{AM Ecosystem}

Economic consequences of AM can hardly be discussed at a single user level. As coined by Jennifer Lawton (president at MakerBot), " $3 D$ printing is an ecosystem, not a device" (Conner 2013). Thus, it is important to develop an understanding of the different elements that constitute this ecosystem which go far beyond sole manufacturing resources and industrial users. Figure 4.1 provides an overview of the components of such an ecosystem.

Though AM is a manufacturing technology, it needs to be considered in the context of digital value chain activities (Brody and Pureswaran 2013; Rayna and Striukova 2014). This is why the ecosystem encompasses activities along a combination of both a conventional manufacturing value chain and a digital value chain of content (product design) creation and distribution. Manufacturing value chains

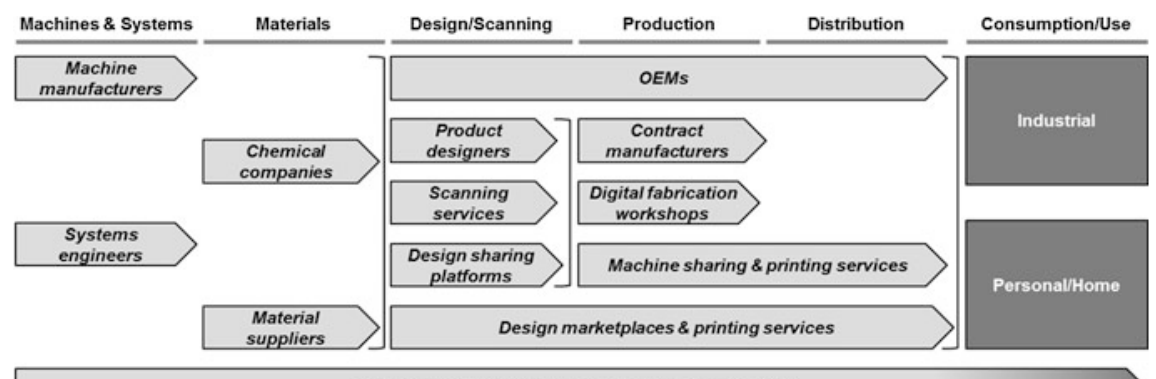

User innovators/entrepreneurs and Maker community

Software/IT (e.g., 3D modelling, IP rights management, IT security)

Research \& Education (e.g., mechanical engineering \& material science, qualityfesting standards, workforce skills)

Policy (e.g., IP rights, CO2e regulation)

Fig. 4.1 AM ecosystem 
frequently include activities related to supply, $R \& D$, production, distribution and the use of a final product (Rayport and Sviokla 1995). Digital value chains differ in regard to its primary object of transactions: it is, by definition, information or digital content (Walters 2012). AM's capability of direct digital manufacturing is frequently highlighted-besides raw materials, it is only the digital product design (CAD) file needed functioning as a universal interface (Berman 2012; Lipson and Kurman 2013; Tuck et al. 2008). Thus, elements of a value chain for digital manufacturing would need to encompass elements such as software, policy (i.e., IP rights), or online services and online 3D design marketplaces.

While most innovation for the manufacturing value chain has been driven by large conventional companies in a BtoB-setting, innovation in the digital value chain has been the result of a growing community of "Makers", i.e. hobbyists, private consumers, and small start-ups interesting in utilizing AM for local manufacture of objects for own use. This community has been very active in developing 3D models, creating an infrastructure for sharing these models digitally in online repositories (like Thingiverse or Google 3D Warehouse), selling 3D printed products on marketplaces, and even developing their own 3D printers for home usage (De Jong and de Bruijn 2013; Gershenfeld 2005; Lipson and Kurman 2013).

We argue that this Maker community has become a kind of "economic lab", experimenting with different designs of value chain and business models, which also provides insight for large scale industrial use of AM. Much of the development of AM innovation in this Maker community has been driven by a mindset of opensource hardware and "Creative Commons" licences. Still, various for-profit businesses emerged successfully from this ecosystem. For example, what started as an open-source project for personal 3D printers (the RepRap project), was further developed and commercialized with the 'Makerbot', a New York based company that became object of a large acquisition by one of the core companies of commercial AM technology (see next section). The upcoming of sustainable business models for AM hence may be similar to the early days of personal computing, where early PC development took place in the "Homebrew Computer Club", developing then into commercial PC makers (Apple etc.), or of digital music distribution, where file sharing communities like Napster developed into commercial online music platforms like iTunes (Anderson 2012; Berman 2012; Lipson and Kurman 2013).

\subsection{Examples of Existing AM Businesses}

Today, a variety of business model exist that cover different activities in the AM ecosystem. In the following, we present some examples of key players in this domain to illustrate how pioneering firms already use AM in their businesses.

Shapeways, one of the first movers in this market, is a 3D model marketplace and production service. It is estimated that they hold a market share of about $70 \%$ (Ponfoort et al. 2014). The idea of Shapeways is to connect designers with consumers, thereby collecting a certain service and production fee. i.materialise is 
using a similar business model. Thingiverse, on the other hand, is a communitybased design sharing platform, operated by Makerbot (owned by Stratasys). The main idea behind this platform is to promote the use of home $3 \mathrm{D}$ printers, in particular Makerbot devices.

FabLabs also aim at promoting the use of 3D printing, however, they are not profit-oriented and work closely together with universities and research centres. These labs provide access to local digital fabrication tools (e.g., 3D printer, laser cutter). TechShops commercially provide a similar digital fabrication infrastructure on a pay-by-use basis. $3 D H u b s$ is a platform to find nearby $3 \mathrm{D}$ printers. The idea is to share existing capacity of locally available printers. $3 \mathrm{D} \mathrm{Hubs}$ as the match-maker charges a service fee to users. This platform is thus using the advantage of 3D printing as a local production facility.

If files for printing are not downloaded from a design sharing platform like Thingiverse, they need to be generated and altered. Already existing objects may be scanned, using a 3D scanner. NextEngine or Makerbot offer such a product. CAD software, as provided by Autodesk, may then be used to edit such files. Alternatively, it can of course be used to generate 3D design files from scratch. Finally, there are, of course, machine manufacturers, such as 3D Systems or Stratasys who offer 3D printers in various price ranges for both, industrial and home use.

Indications of growing market confidence in the sustainability of business models relying on 3D printing offerings include the recently announced acquisition of Makerbot by Stratasys for US\$403 million (Stratasys 2013). Furthermore, dedicated investment funds have been launched that track the performance of the AM sector. Building on AM technology in general and the aforementioned business models in particular, a variety of opportunities for innovation and entrepreneurship arise.

\subsection{How AM Facilitates User Innovation and Entrepreneurship}

The history of technology taught us that innovation and new business models are frequently developed outside firms' R\&D departments (Von Hippel 2005). Userdriven innovation appears where problems are directly observed and corresponding solutions are developed. AM facilitates transforming ideas into physical products, and to turn user innovators into manufacturers and entrepreneurs. Thus, user entrepreneurs may become independent of established producers' manufacturing resources to (locally) commercialize their innovations with their own business models. 


\subsubsection{Local Manufacturing and 3D Printing at Home}

A distinctive feature of AM is frequently emphasized in the popular press: its ability to be placed locally next to potential users, up to the point of locating a 3D-printer into a user's home (Berman 2012; De Jong and de Bruijn 2013; The Economist 2011; Vance 2012). Physical products have usually been manufactured at a production site far from the location of end user. For many products fixed costs in conventional production lead to economies of scale. Some products are also simply too difficult to produce or to assemble for a regular user, there is a need for specific knowledge or tools which are costly to get. The downside of this way of producing is typically some kind of missing fit of the final product. Some products are needed "right away", others are produced in a standard setting at the manufacturer while users have a preference for a variety. Moreover, some products require a try-on and rework, again resulting in disutility for the user.

If this disutility overweighs the economies of scale in production, there is scope for local manufacturing at the point of use. This feature is exactly the core of the business model of $3 \mathrm{D} \mathrm{Hubs}$. One of the key characteristics of AM is that it dramatically reduces the benefit of conventional economies of scale. As a result, local manufacturing could become profitable. Anecdotic evidence supports this observation: The price of personal 3D printers has decreased several magnitudes within the last 5 years, leading to a growth in the installed base of this machinery of 50-400\% annually (Wohlers 2013). In addition, an accessible local manufacturing infrastructure based on AM is in the upcoming. Companies like TechShop or nonprofit institutions such as FabLabs provide local access to AM, comparable to the "copy shop" around the corner. Thus, it is likely that an increasing number of users will direct access to local $3 \mathrm{D}$ printing resources in the near future.

\subsubsection{User Innovation and AM}

Local production may be foremost attractive for innovating users. Past research has shown that users have been the originators of many industrial and consumer products (Von Hippel 2005). Especially when markets are fast-paced or turbulent, these lead users are becoming a major source of innovation. Recent development in IT have lowered the cost for users to innovate: steadily improving design capabilities that advances in computer hardware and software make possible; improved access to easy-to-use development software; and the growth of a steadily richer innovation commons that allows individual users to combine and coordinate their innovation-related efforts via the internet. But there has been a "missing link" (Skinner 1969) in user innovation: manufacturing. Many (lead) users lack the resources and capabilities to turn their inventions into "real" products beyond prototypes, i.e., products with the same properties like industrially manufactured goods. Hence, users often freely revealed their innovations to manufacturers 
(Harhoff et al. 2003), benefiting from their capabilities to produce the product in an industrial and stable quality. Manufactures, in turn, benefited from taking up this task by the opportunity to sell these products also to other customers, hence providing a distribution channel for the user invention. For broader development of user innovations, however, this system relied on the availability and willingness of a manufacturer to take up a user innovation.

AM could change this process. Users can turn to advanced AM technologies to produce smaller series of products for themselves and their peers. User innovation then will be supplemented by user manufacturing, which we define as the ability of a user to easily turn her design into a physical product. By eliminating the cost for tooling (moulds, cutters) and switching activities, AM allows for an economic manufacturing of low volume, complex designs with little or no cost penalty. AM further enables multiple functionality to be manufactured using a single process, including also secondary materials (like electrical circuits), reducing the need for further assembly for a range of products. In addition, integrated functionality can replace the need for surface coatings and textures (Wohlers 2013). All these characteristics make AM a perfectly suited manufacturing technology for user manufacturers.

\subsubsection{User Entrepreneurship and AM}

With this production capacity available, user manufacturers may turn into user entrepreneurs. Recent research found that innovating (lead) users frequently engage in commercializing their developments (Shah et al. 2012). Accordingly, the term user entrepreneurship has been defined as the commercialization of a new product and/or service by an individual or group of individuals who are also innovative users of that product and/or service (Shah and Tripsas 2007). User entrepreneurs experience a need in their life and develop a product or service to address this need, before founding the firm. As a result, user entrepreneurs are distinct from other types of entrepreneurs in that they have personal experience with a product or service that sparked innovative activity and in that they derive benefit through use in addition to financial benefit from commercialization.

The option for local production via AM will also benefit user entrepreneurs. First of all, the sheer opportunity to get access to a flexible manufacturing system without investing in high fixed cost may turn more lead users into user entrepreneurs. In particular, the new product development process can be facilitated when AM is employed. Efforts both in terms of costs and time can be largely reduced with access to local AM resources, while design iterations do not involve cost penalties (no tooling). Once user entrepreneurs started commercializing their products, they may have a competitive advantage against established manufacturers as they obtain better local knowledge on customer demand, allowing them to design products closer to local needs. Especially in a situation where customer demand is heterogeneous and customers place a premium on products fitting exactly to their 
needs, local producers may outperform established manufacturers of standard goods. The benefits of offering a better product fit may outweigh disadvantages in manufacturing costs due to economies of scales achievable by the established firm with its standard offering. A system of entrepreneurial user manufacturers could have large impact on the market structure in a given industry.

Interestingly, entrepreneurs do not need to acquire their own manufacturing resources. Instead, they might use the existing AM ecosystem and rely on a 3D printing service (like Shapeways, as described before) or contract manufacturer to produce their goods - the interface is rather simple: the product's 3D design file. Thus, AM reduces barriers to market entry as fixed costs for production are largely eliminated.

\subsection{Conclusions}

Concluding, we propose that AM will largely influence the locus of innovation and production, enabling the design of new value chains and business models. To achieve economies of scale, many physical products have previously been manufactured far from the site of end use. This can sometimes create high costs for the user due to the lags involved in acquiring something physical that is needed "right away" and "just as I like it". In these cases, AM of physical products at the point of use can make sense even if it comes with high production costs per unit. This market demand, in turn, induces development of on-site manufacturing methods and equipment. Once these are available, they tend to become progressively cheaper and serve larger segments of the market.

However, the future development of AM and its applications are hard to predict, which is mainly caused by the fact that AM is embedded in a large ecosystem with a variety of actors with different capabilities and interests. Users might play a significant role in this ecosystem. They successfully demonstrated their innovating power in the past; now, as they get increasingly more access to local manufacturing resources (formerly, the "missing link"), it is likely that the triad of user innovation, user manufacturing and user entrepreneurship is fuelled. The current rise of a Maker community utilizing, but also developing AM technologies, is a string indicator for this opportunity. In turn, established firms need to rethink their existing business models and adapt a different role in the ecosystem, for example one of a platform operator, marketplace or service provider.

Naturally, there are also opposing drivers, so the question whether production will shift toward a system of local manufacturing is non-trivial: First, under competition, existing manufacturers may react with pricing and/or product enhancements, increasing the appeal of their offerings. Secondly, it has been shown that the strive for economies of scale in a centralized conventional manufacturing system has established a strong and very proven regime that is difficult to break up. Finally, the threshold to engage in own manufacturing may be high for many users. Consider the case of digital photo printing: After a strong rise of home photo printers, the market 
today has equally divided into decentralized printing kiosks in drugstores and large scale, centralized labs served via the internet. At-home printing of glossy photos however has strongly diminished. Are these transitional adaption effects or structural constraints? Future research has to show.

Open Access This chapter is distributed under the terms of the Creative Commons Attribution Noncommercial License, which permits any noncommercial use, distribution, and reproduction in any medium, provided the original author(s) and source are credited.

Acknowledgment The authors would like to thank the German Research Foundation DFG for the kind support within the Cluster of Excellence "Integrative Production Technology for HighWage Countries.

\section{References}

Anderson, C. (2012). Makers: The New Industrial Revolution. Random House.

ASTM International. (2012). ASTM F2792-12a: Standard Terminology for Additive Manufacturing Technologies. ASTM International. Retrieved from www.astm.org/Standards/F2792. htm

Atzeni, E., \& Salmi, A. (2012). Economics of Additive Manufacturing for End-usable Metal Parts. The International Journal of Advanced Manufacturing Technology, 62(9-12), 1147-1155.

Berman, B. (2012). 3-D Printing: The New Industrial Revolution. Business Horizons, 55(2), $155-162$.

Brody, P., \& Pureswaran, V. (2013). The new software-defined supply chain. IBM Institute for Business Value. Retrieved July 12, 2013, from http://public.dhe.ibm.com/common/ssi/ecm/en/ gbe03564usen/GBE03564USEN.PDF

Conner, C. (2013). "3D Printing Is An Ecosystem, Not A Device": Jennifer Lawton, MakerBot. Forbes September 13, 2013. Retrieved from http://www.forbes.com/sites/cherylsnappconner/ 2013/09/13/3d-printing-is-an-ecosystem-not-a-device-jennifer-lawton-makerbot/

De Jong, J. P., \& de Bruijn, E. (2013). Innovation lessons from 3-D printing. MIT Sloan Management Review, 54(2), 43-52.

Dolgui, A., \& Proth, J.-M. (2010). Supply Chain Engineering: Useful Methods and Techniques. London: Springer.

Gartner. (2012). Hype Cycle for Emerging Technologies August 2012. Retrieved from http:// www.gartner.com/newsroom/id/2124315

Gartner. (2014, January 9). Gartner's 2014 Hype Cycle for Emerging Technologies. Retrieved July 17, 2014, from http://www.gartner.com/newsroom/id/2819918

Gershenfeld, N. A. (2005). Fab: The Coming Revolution on Your Desktop. New York, NY: Basic Books.

Gibson, I., Rosen, D. W., \& Stucker, B. (2010). Additive Manufacturing Technologies: Rapid Prototyping to Direct Digital Manufacturing. New York, London: Springer.

Harhoff, D., Henkel, J., \& von Hippel, E. (2003). Profiting from Voluntary Information Spillovers: How Users Benefit by Freely Revealing their Innovations. Research Policy, 32(10), 1753-1769.

Koren, Y. (2006). General RMS characteristics. Comparison with with dedicated and flexible systems. In A. Dashchenko (Ed.), Reconfigurable Manufacturing Systems: 21st Century Technologies (pp. 27-45). London: Springer.

Kurfess, T., \& Cass, W. J. (2014). Rethinking Additive Manufacturing and Intellectual Property Protection. Research-Technology Management, 57(5), 35-42. 
Lipson, H., \& Kurman, M. (2013). Fabricated: The New World of 3D Printing. Indianapolis, IN: John Wiley \& Sons.

Mellor, S., Hao, L., \& Zhang, D. (2014). Additive Manufacturing: A Framework for Implementation. International Journal of Production Economics, 149, 194-201.

Petrovic, V., Vicente Haro Gonzalez, J., Jordá Ferrando, O., Delgado Gordillo, J., Ramón Blasco Puchades, J., \& Portolés Griñan, L. (2011). Additive layered manufacturing: sectors of industrial application shown through case studies. International Journal of Production Research, 49(4), 1061-1079.

Ponfoort, O., Ambrosius, W., Barten, L., Duivenvoorde, G., van den Hurk, L., Sabirovic, A., \& Teunissen, E. (2014). Successfull business models for 3D printing: seizing opportunities with a game changing technology. Utrecht: Berenschot.

Rayna, T., \& Striukova, L. (2014). The Impact of 3D Printing Technologies on Business Model Innovation. In P. Benghozi, D. Krob, A. Lonjon, \& H. Panetto (Eds.), Digital Enterprise Design \& Management (Vol. 261, pp. 119-132). Cham: Springer International Publishing.

Rayport, J. F., \& Sviokla, J. J. (1995). Exploiting the virtual value chain. Harvard Business Review, 73(6), 75.

Ruffo, M., \& Hague, R. (2007). Cost estimation for rapid manufacturing: simultaneous production of mixed components using laser sintering. Proceedings of the Institution of Mechanical Engineers, Part B: Journal of Engineering Manufacture, 221(11), 1585-1591.

Shah, S. K., \& Tripsas, M. (2007). The accidental entrepreneur: The emergent and collective process of user entrepreneurship. Strategic Entrepreneurship Journal, 1(1-2), 123-140.

Shah, S. K., Winston Smith, S., \& Reedy, E. J. (2012). Who are user entrepreneurs? Findings on Innovation, Founder Characteristics \& Firm Characteristics. Kansas City, MO: Kauffman Foundation.

Skinner, W. (1969). Manufacturing: Missing link in corporate strategy. Harvard Business Review, 47(3), 136-145.

Stratasys. (2013). Press Release: Stratasys to Acquire MakerBot, Merging Two Global 3D Printing Industry Leaders. Retrieved from http://investors.stratasys.com/releasedetail.cfm?ReleaseID= 772534

The Economist. (2011). Print me a Stradivarius. The Economist, February 10, 2011.

Tuck, C. J., Hague, R. J. M., Ruffo, M., Ransley, M., \& Adams, P. (2008). Rapid Manufacturing Facilitated Customization. International Journal of Computer Integrated Manufacturing, 21(3), $245-258$.

Vance, A. (2012). 3D Printers: Make Whatever You Want. BusinessWeek: Technology April 26, 2012. Retrieved from http://www.businessweek.com/articles/2012-04-26/3d-printers-makewhatever-you-want

Von Hippel, E. (2005). Democratizing Innovation. Cambridge, MA: MIT Press.

Walters, D. (2012). Competition, Collaboration, and Creating Value in the Value Chain. In H. Jodlbauer, J. Olhager, \& R. J. Schonberger (Eds.), Modelling Value (pp. 3-36). Heidelberg: Physica-Verlag.

Wilbanks, K. B. (2013). The Challenges of 3D Printing to the Repair-Reconstruction Doctrine in Patent Law. George Mason Law Review, 20(4).

Wohlers, T. T. (2013). Wohlers Report 2013. Fort Collins, CO: Wohlers Associates. 